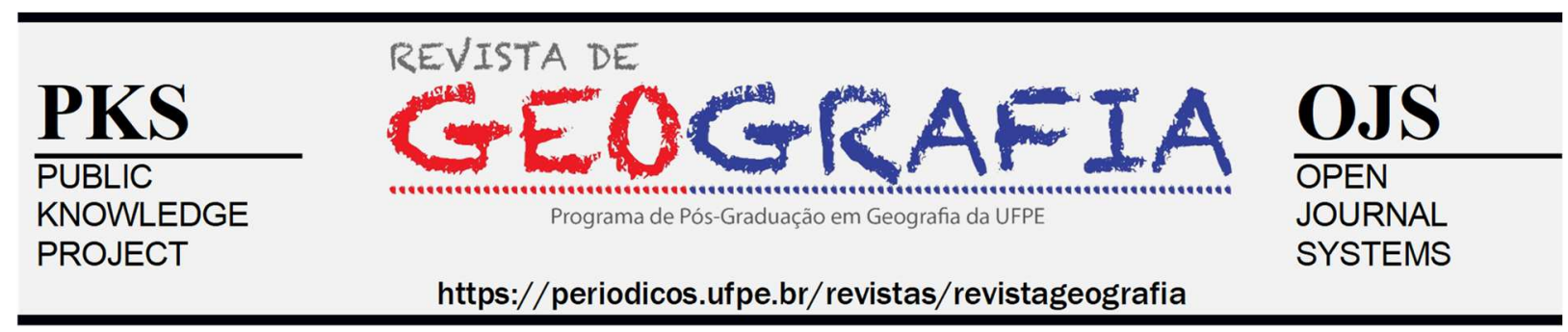

\title{
O PENSAMENTO GEOGRÁFICO E A FORMA DO MUNDO
}

\author{
Vitor Bessa Zacché ${ }^{1}$ \\ ${ }^{1}$ Doutorando em Geografia pela Universidade Federal do Espírito Santo, E-mail: vitorzacche@gmail.com. \\ ORCID: http://orcid.org/0000-0001-5813-849X
}

Artigo recebido em 03/03/2020 e aceito em 16/02/2021

\begin{abstract}
RESUMO
Este artigo é resultado da reflexão em torno da teoria da terra plana e o pensamento geográfico. Essa teoria ocorre como um fenômeno e vem se difundindo no Brasil por meio da internet desde 2015. As contradições decorrentes de tal tema são inúmeras e normalmente não repercutem no reduto acadêmico. No entanto, torna-se necessário avaliar os fundamentos da questão à luz da geografia, uma vez que são análogos à sua base investigativa "o que é o mundo"? Para isso, a discussão foi situada no encalço geográfico balanceando o heliocentrismo diante do geocentrismo, situando o método geográfico e problematizando-o em relação ao empirismo.
\end{abstract}

Palavras chave: Heliocentrismo; Terra plana; Pensamento Geográfico

\section{GEOGRAPHICAL THINKING AND THE FORM OF THE WORLD}

\begin{abstract}
This article is the result of reflection on flat earth theory and geographic thinking. This theory occurs as a phenomenon and has been spreading in Brazil through the internet since 2015. The contradictions covered by this theme are numerous and usually do not speak in the academic stronghold, however it is necessary to evaluate the fundamentals of the issue in the light of geography since they are analogous to their investigative base "what is the world"? For this, the discussion was situated in the geographical pursuit balancing the heliocentrism before the geocentrism, situating the geographical method and problematizing it regarding empiricism.
\end{abstract}

Keywords: Heliocentrism; Flat Earth; Geographic Thinking

\section{INTRODUÇÃO}

Atualmente tem-se constatado nos veículos de comunicação brasileiros o surgimento de um assunto bastante controverso aos termos da geografia, trata-se da "teoria da terra plana". Embora bastante inusual para os tempos presentes, essa teoria tem se apresentado sob diversos aspectos e vem ganhando adeptos, principalmente no Brasil, culminando com a primeira conferência da terra plana realizada em novembro de 2019, em São Paulo. 
Tal fenômeno, que tem invadido as redes sociais e vem causando rebuliço nas salas de aula, vai de encontro às premissas geográficas amplamente difundidas sobre a forma de nosso planeta. No entanto, o avanço dessa teoria compete o retorno aos tempos em que isso já fora discutido.

Nesse sentido, assiste-se a uma regressão filosófica em pleno século XXI, remetendo o pensamento geográfico à sombra da dúvida, ou seja, mesmo com todas as evidências de uma terra plana, existem pessoas que não aceitam essa teoria, e, mesmo com todas as evidencias de uma terra globo, existem pessoas que também não aceitam tal teoria.

Vale ressaltar que isso já fora assim. Em "22 de junho de 1633, é pronunciada a sentença da proibição do Diálogo e Galileu é obrigado, com vestes de penitente, a recitar publicamente e assinar a abjuração no mosteiro de Santa Maria sobre Minerva" (GALILEI, 2011, p.65).

O pequeno trecho acima relata a abjuração de Galileu ao "copernicismo", essa discussão entre o sistema geocêntrico e heliocêntrico tem datação antiga e é marcada profundamente por um contexto religioso, destacando o fato que, em princípio, a igreja não aceitou a tese heliocêntrica, o que fundamentou a abjuração de Galileu para evitar as chamas da inquisição.

Percebe-se, então, que desde o apagar de tais chamas o mundo é esférico e isso era um ponto indiscutível até a aparição do fenômeno "terraplanista" que remonta um cenário de dúvidas e manifestações contraditórias, mesmo com as evidencias interespaciais amplamente difundidas. O que percebe-se no chão firme da Terrra são os questionamentos ressurgindo e difundindo-se.

A geografia situa o planeta no modelo heliocêntrico, porém, não foi sempre assim. A geografia de Humboldt em sua obra Cosmos é marcada por uma série de entendimentos que foram subtraídos da geografia com a ascensão das ideias de Nicolau Copérnico e seus sucessores, evidenciando a ruptura entre o estudo da cosmografia e o engessamento da geografia ao modelo científico moderno.

A reflexão sobre o que é o mundo sempre fora uma das chaves mestras da geografia, porém a ascensão tecnológica fez com que a mesma ficasse de fora das evidenciações sobre o assunto, que foram assumidas pela física e a astronomia, por exemplo. De modo geral, a 
geografia passa a enxergar o mundo não mais com seus olhos ou seu empirismo, mas com os olhos e olhares de outras ciências.

Assim, o que se encontra em estado de análise é o pensamento geográfico e as suas premissas fundamentais, uma vez que tal constructo moderno de uma terra plana remete-o, e por isso faz-se a reflexão sobre tal condição atual.

\title{
A GEOGRAFIA E A FORMA DA TERRA
}

Ao tratar-se da geografia e suas aplicações sobre a forma do mundo, observa-se que seu trajeto medieval não apresenta discussões mais acirradas sobre o assunto, os séculos antecedentes ao Renascentismo foram contemplados, geograficamente, por um acervo descritivo, porém com poucas contestações ou formulações teóricas sobre o tema em questão.

A Idade Média foi moldada firmemente em um imaginário geográfico para além do empirismo, fato esse constatado por diversos peregrinos da época que trouxeram em seus relatos medidas, quantificações e formas, moldando um apanhado de relatos e cosmologias que fazem dessa fase a 'idade das trevas' também para a geografia. destaca que

Em um estudo apurado sobre a geografia na idade média, Kimble (2005, p.51)

\begin{abstract}
a geografia do século IV é essencialmente a geografia do século VIII e é de fato muito pouco diferente daquela do século XV, pois Colombo (como Alexandre Von Humboldt primeiramente observou) tirou muitas de suas ideias de Pierre D'Ally, que bebeu-as amplamente de Roger Bacon o qual, por sua vez, foi fortemente influenciado pelos primeiros padres.
\end{abstract}

Entende-se que a geografia então se estabelecia com uma característica descritiva sobre os lugares remotos, fato que pavimentava o imaginário e que a manteve assim até meados do século XVI, quando que com a necessidade das grandes navegações inicia-se um fluxo de transição para as novas formulações geográficas postuladoras bastante incipientes da situação atual do pensamento geográfico.

Em tempos de revolução cientifica, a geografia não ficara fugidia a esse momento, "do período de tempo que vai mais ou menos da data da publicação do De Revolutionimbus de Nicolau Copérnico, isto é, de 1543, à obra de Isaac Newton, Philosophiae naturalis principia mathematica, que foi publicada pela primeira vez em 1687" (REALE, ANTISERI 2007, p.196). 
Uma mudança na imagem do mundo fora suscitada em meio a esse período, "a revolução astronomica', que teve seus representantes mais prestigiosos em Copérnico, Tycho Brahe, Kepler e Galileu e que confluiria para a "física clássica" de Newton" (REALE, ANTISERI 2007, p.197), permitiu ao pensamento geográfico uma dimensão global.

Uma das expressas contribuições para essa transição deu-se por Bernhardus Varenius, sua obra é expressão da indução de um modelo matemático ao pensamento geográfico. "Varenius compartilhou daquilo que koyré (2001) considerou como característica central da ciência moderna, que é a unificação do universo mediante leis válidas igualmente em todos os lugares e mediante as regras da geometria” (BAUAB, 2011, p.219).

Antecessor de Humboldt, ocupava-se de um raciocínio matemático para a explicação dos fenômenos da natureza observáveis na Terra. "O raciocínio matemático aparece em Varenius, como elemento que antecede e que deve fundamentar a experiência, fornecendo um fio seguro por onde pode trafegar tranquilamente o pensamento" (BAUAB, 2011, p.215).

Essa característica não se difere muito dos postulados da época que necessitavam de teorias e formulações para sustentar o universo que se abrira com essas revoluções, "no curso desse processo, à medida que assume consistência a nova forma de saber que é a ciência moderna, a outra forma de saber - isto é, a magia - passa a ser combatida como forma de pseudociência e de saber espúrio" (REALE, ANTISERI 2007, p.198).

Seu modo de pensar geograficamente se deu por um sentido prático, optando por respostas precisas que se enquadrassem dentro de um modelo sistêmico, cujo cálculos pudesse levar a precisão dos resultados.

\begin{abstract}
Num contexto histórico de ampla mobilidade espacial, de criação de uma teia de rotas marítimas cada vez mais globais, Varenius visa claramente reformar e normatizar o conhecimento geográfico com o claro propósito de responder à frequente demanda por exatidão que concerne às informações relativas ao nosso planeta, oferecendo uma imagem revigorada de mundo" (BAUAB, 2011, p.217).
\end{abstract}

A obra de Varenius faz valer o salto do geocentrismo para o heliocentrismo, cujo os fenômenos só são capazes de serem explicados por meio da matemática, fato esse que corrobora com as ideias newtonianas, tira de evidência o criador, e destaca a criação em si mesma. "E, mais, o principio vegetativo do mundo, principio organizador do pensamento alquímico, esteve sempre presente na obra Newtoniana, agora, transformado em espaço absoluto e na matematização dos fenômenos físicos, onde o cálculo demonstraria o design divino" (VITTE, 2013, p.87). 
Uma nova luz à ciência, com ampla participação na reforma da igreja o

Copernicismo transformou-se em heliocentrismo, com forte impacto na filosofia natural; acrescida pelo uso do cartesianismo, o que possibilitou a dessacralização da natureza, o estudo detalhado de seus elementos constitui-se várias escalas por meio da descrição da natureza. Acrescentaríamos que esta foi a base para a construção de uma nova ciência, no caso a geografia (VITTE, 2013, p.90).

Em um sentido mais específico e atribuído ainda à sobreposição dos modelos matemáticos sob às explicações teológicas, "o geocentrismo nos países baixos e na Alemanha promoveu o heliocentrismo, fugindo as explicações herméticas e valorizando a matematização e o conhecimento da filosofia natural" (VITTE, 2013, p.92).

Logo, "a geografia geral de Varenius é um marco na ciência moderna, pois foi a primeira ciência que de fato assumiu a separação entre o homem e a natureza, entre o homem e deus; abrindo caminho para a revolução newtoniana que estaria por vir" (VITTE, 2013, p.97).

Embora a realidade sobre o modelo heliocêntrico esteja disseminada no pensamento geográfico moderno, sua vanguarda carrega questões que se mostram insolúveis ainda na atualidade, pois sua similaridade com o mundo real apresentado no modelo em questão é majoritariamente contemplada através de obras de arte, ficção e consequente imaginação.

A própria situação da utilização dos instrumentos científicos no âmbito da revolução cientifica fora alvo de contestações, uma vez que esses "tornam-se parte do saber científico, não um saber cientifico separado, e ao seu lado, os instrumentos; os instrumentos estão dentro da teoria, tornando-se teorias, eles próprios” (REALE, ANTISERI 2007, p.196).

A geografia que surge nesse momento histórico em que os aparelhos de medições, diga-se, os equipamentos dos geógrafos ainda estavam incipientes à utilização, aprimoramentos, testes e obsolescência, contextualizam com o avanço do pensamento geográfico até a atualidade e contribuem de uma forma ou outra com a ascensão da geografia moderna e contemporânea.

Notavelmente, a precisão traçada pela instrumentalização das ciências de um modo geral deu à geografia uma nova roupagem para se alinhavar à descrição precisa da superfície terrestre, estabelecendo uma teia de informações geográficas sobre o planeta muito além das formulações medievais, porém deixa a questão da forma do planeta posta de lado, uma vez que confiou aos instrumentos científicos e suas teorias adjuntas tal questão. 
Embora os avanços visíveis na atualidade tecnológica sejam implacáveis, nota-se que, tanto nos livros quanto nas imagens, o que nos remonta a configuração de universo é reproduzido através da arte, seja nas telas ou nos livros didáticos. Quando empiricamente constatado, o que nos salta aos olhos remete à muitas diferenças do que nos é ensinado. Hawking (2001, p.51) menciona que "da perspectiva positivista, entretanto, não determinamos o que é real. Tudo o que podemos fazer é achar que modelos matemáticos descrevem o universo em que vivemos".

Nesse sentido, as inferências realizadas por outras teorias ao modelo heliocêntrico, principalmente no que tange o tríplice movimento da terra e sua esfericidade, são passíveis de investigação no âmbito da geografia, uma vez que, na educação em geral somos imersos em um saber estabelecido, que suprime qualquer indagação.

A priori, esse tema já teria sido tratado e solvido, desde que Maupertuis, em 1736, "em Tornio perto do círculo polar ártico, começou a medir sua linha de base" (FERNANDEZ, 2009, p. 354). Ele havia chegado ao ponto mais setentrional da Terra por mar.

Sua façanha ilustrada na obra Os desbravadores, "ainda que fosse praticamente impossível de obter precisão absoluta; suas descobertas bastaram para convencer o mundo de que o planeta era realmente um esferoide oblato - achatado nos polos" (FERNANDEZ, 2009 p. 354).

Eis que sua tese a partir de sua prática é aceita como conclusa, porém é interessante destacar que:

\footnotetext{
Maupertuis acabou desiludido com a ciência e encantado com a natureza. No começo de sua expedição, acreditava que toda verdade seria quantificável, e que todo fato poderia ser captado pelos sentidos. Terminou-a quase como místico [...] as experiências de Maupertuis sucitaram profundas incertezas em seu íntimo sobre o valor da ciência (FERNANDEZ, 2009 p. 355).
}

Exprime-se por essa representação contida em Maupertius que a dúvida se apresentou solvida para o âmbito científico, porém ainda se perpetuou junto à vida dele, quando concluiu mesmo após a descoberta, que "talvez ainda não estejamos prontos para compreender o mundo de maneira sistemática - mas apenas para contempla-lo, maravilhados." (FERNANDEZ, 2009 p. 355).

Essa inquietude perpassa os desbravadores, como Maupertius, e perpetua-se até Humboldt. Em sua obra Kosmos há questões que detém como tema referência a descrição 
física do mundo e a forma da terra, o pensamento geográfico nasce com essa questão e mantém-se uma questão chave da geografia até intermédios do século XIX.

Atentando-se ao "terceiro volume do Kosmos, publicado em 1850 com 645 páginas e, apresenta-se sob duas grandes partes - a parte uranológica da descrição física do mundo e O sistema solar;" (LOURENÇO, 2003, p.56) nota-se a conexão com a questão já no gérmen do pensamento geográfico.

Em um dado momento a questão da forma da Terra fora cunhada pelo discurso da geografia. Atualmente, observa-se que a opinião geográfica de formato do mundo é cunhada por outras ciências, postulando o caráter do empirismo geográfico a um padrão secundário.

Humboldt apontava o conhecimento da

conexão das forças da natureza, o sentimento íntimo de sua dependência mútua [...] sendo assim, a geografia de Humboldt não é um estudo das singularidades locais, pauta-se numa ideia de unidade da natureza e da terra, aspira conhecer a ação simultânea e o vasto encadeamento das forças que animam (MORAES, 2002 p.108).

Na obra "A Revolução Copernicana", referindo-se a Copérnico, Kuhn aponta que, "pela primeira vez, um astrônomo tecnicamente competente rejeitara uma tradição científica honrada pelo tempo por razões internas da sua ciência, e este conhecimento profissional da falácia inaugurou a revolução copernicana” (KUHN, 1975 p.164).

As ideias de Copérnico não demoraram a se difundir, Richard Morris elenca tal episódio sob o seguinte aspecto:

Os astrônomos foram rápidos em reconhecer a importância da obra de Copérnico.
Poucos deles se dispuseram a aceitar a ideia de que uma Terra gira em torno do sol.
Percebiam, contudo, que as ferramentas teóricas que Copérnico desenvolvera eram
úteis para o cálculo das posições dos planetas e estavam prontos para aceitar a ideia
de uma terra em movimento como uma ficção matemática útil (MORRIS, 1998
p.149).

Já com referência a aplicabilidade dos métodos matemáticos advindos da obra de Copérnico, e reproduzidos a partir de Kepler, Tycho Brayer e Galileu, o autor evidencia ainda a didática adotada pelo matemático francês Jean Le Rond d’Alembert, que "afiançava a seus alunos que realmente valia a pena estudar aqueles métodos duvidosos. O cálculo, ele lhes dizia, pode parecer ilógico de início, mas com o tempo eles alcançariam a fé" (MORRIS, 1998 p. 79). 
Já o autor Silvio Seno Chibeni pondera acerca do conhecimento estabelecido a partir ciência moderna.

\begin{abstract}
Se enquanto cientistas e filósofos, estamos procurando elaborar uma imagem coerente e compreensível do mundo, capaz de acomodar, pelo menos de modo aproximado ou programático a totalidade de nossas experiências básicas, não podemos nos contentar nem com a postura de Bohr e seus simpatizantes, nem com o mundo da física clássica. (CHIBENI, 1997, p.180)
\end{abstract}

Em um tom de questionamento ao conhecimento estabelecido, o mesmo autor ainda pontua: "o mundo determinista de Newton - Maxwell - Einsten aparentemente não tem lugar para a existência de seres genuinamente livres" (CHIBENI 1997 p.180).

Humboldt mantinha uma posição claríssima: "a geografia física é a parte terrestre da cosmografia, e o Cosmos é assumidamente um estudo geográfico" (MORAES 2002 p.103), no entanto, a ocorrência da ruptura resultante em cosmografia e geografia é fortalecida com o avanço das tecnologias, culminando com a separação e supressão da cosmografia.

Embora Copérnico tivesse suprimido o geocentrismo entre os séculos XV e XVI, a velocidade com que ocorreram os fatos pulverizaram as dúvidas. "Quando Copérnico terminou de acrescentar círculos, o seu sistema complicado centrado no sol deu resultados tão exatos como o de Ptolomeu, mas não deu resultados mais exatos” (KUHN 1975 p.199).

Por esse aspecto, a postura de Humboldt em sua análise de mundo é controversa ao copernicismo, uma vez que sua interpretação pauta o cosmos como parte da Terra, o que denota um diálogo mais claro com o geocentrismo, uma vez que na cosmografia das sagradas escrituras a terra era centro do universo.

Seus estudos pautados no empirismo revelaram associações antes não estabelecidas entre altitude, clima e vegetação, o que faz com que seu trabalho seja interpretado ainda como botânica e áreas afins, e não geografia.

A conjuntura de fatores filosóficos e políticos para a abordagem de tais conteúdos dão-se ainda sob a égide dos questionamentos pós-modernos, sobre o modelamento imposto pela ciência e pela técnica à cultura de um modo geral. Esse teor impregna a construção geográfica e a remete enquanto modelo de fácil reprodução, fato que leva ao esquecimento ou obsolescência factual das essências e de outros parâmetros.

Remeter o pensamento ao que é o mundo sempre foi uma constante nas reflexões dos seres humanos, no entanto a supressão das ciências sobre tal ato é marcadamente vigente 
através de suas operações que atribuem determinada satisfação às questões que inquietam, porém, que já se superam em uma fase ainda infantil por meio da educação.

Em um apanhado sobre os métodos de Humboldt, constata-se:

Humboldt demonstra que seu método resulta da composição do empirismo com racionalismo, acrescentando aí a importância da história para a compreensão da formação e das causas dos fenômenos (...). Todavia, independente da filosofia especulativa alemã, ou mesmo além dela, é perceptível em Humboldt a do ideal metafísico de um impulso criador, eterno que está por detrás das leis da natureza (BRITO 2015 p. 199).

A entonação de Humboldt para com a natureza e o consequente surgimento da geografia demonstra de maneira ímpar o distanciamento contido na atual forma de construção do pensamento geográfico e sua matriz, que nele habiatava. A condição em que ele posicionava o empirismo é testemunha deste processo, haja vista que o geógrafo moderno pouco necessita de idas fatídicas a campo, pois, tão logo, é atendido e suprido por tecnologias. Professores geógrafos tampouco necessitam, para descrever o mundo, ter conhecimento factual sobre os espaços e suas diversidades seguem a cartilhas determinadas pelo sistema de ensino estabelecido.

Esta perspectiva faz dele não apenas um ilustre cientista moderno. A forma como catalogou e mostrou os dados da natureza não trouxeram a essa uma simples sistematização.

Cada parte carrega em si o universal, que em sua aparência, em um primeiro momento, é imperceptível, mas a combinação das combinações entre ela surge a dinâmica que move o todo. A paisagem representa forma como esse todo se expressa no particular. A imagem capturada pela contemplação revela a perspectiva de uma ligação entre o invisível e o visível, entre o todo e o particular (BRITO 2015 p. 201).

Os ideais humanos atuais perpetuam-se em um cenário originado no iluminismo enciclopedista e na física mecanicista, porém o pensamento geográfico não é oriundo somente deste cenário.

Cabe destaque as diversas expedições que foram feitas em tempo de Humboldt para que fossem reveladas as descobertas das grandes navegações, no entanto, destaca-se a obra dele enquanto selo da geografia, e por esse viés, ancorou-se a condição para o surgimento do pensamento geográfico, ou seja, o despontar da geografia encontra-se atrelado a Humboldt e principalmente ao seu método. 
O método comparativo de Humboldt possibilitara o desvelamento do todo a partir da observação e contemplação dos particulares, do sopro que animas as vidas. Trata-se, segundo Vitte e Silveira (2010, p.189), da busca do arquétipo do infinito, na dimensão do infinito" (BRITO 2015 p. 201).

Salienta-se, por esse contexto que toda sua busca estava atribuída à sua escala, ao seu ponto de observação, a partir de seu próprio corpo e suas descobertas, foi-se consagrando a construção de um pensamento interpretativo da natureza que culminou na geografia.

Porém, há uma distinção chave recorrente entre a forma com que se deu a construção do pensamento geográfico Humboldtiano para o atual, uma vez que, "em Humboldt pode-se perceber na revalorização da sensibilidade na relação sujeito e objeto, provocando no observador seus ideais de harmonia e beleza" (BRITO 2015 p. 202).

Praticamente o que sucinta da obra é a peculiar conjectura estabelecida entre sujeito e objeto que traz o brilho da compreensão, e neste detalhe está a chave comparativa entre o passado e o atual na construção do pensamento geográfico.

Elevando-se a questão, faz-se compreender que o ato de observar, contemplar estava contido na metodologia de Humboldt para além da instrumentalização, entende-se então a condição necessária para se perceber o mundo a partir de uma escala fisiológica, que parte do corpo e dos sentidos.

Advém desse contexto, “o estabelecimento da paisagem como referência escalar para o Homem dá-lhe a dimensão que Humboldt espera poder construir cientificamente, ou seja, a posição entre Homem e o mundo com o fim último da contemplação, logo da teoria" (LOURENÇO 2003, p.71).

O homem, no contexto da paisagem, a contemplar o mundo, lança uma escala que na atualidade está um tanto distante da realidade científica ou do que prega a ciência. $\mathrm{O}$ telescópio Hubble, a estação Espacial (ISS), apresentam ao homem um contexto fora dessa base escalar. Para Peter Sloterdijk, "a estação espacial representa um modelo para estar no mundo condenado a artificialidade" (INGOLD 1948 p. 176).

Tais exemplos confrontam diretamente com uma preocupação essencial do trabalho de Humboldt, que visava ainda "à exposição do princípio da unidade e totalidade da natureza, objetivo mais elevado e declarado dos estudos de Humboldt" (LOURENÇO, 2003, p.72).

Percebe-se, assim, duas vertentes metodológicas para o pensamento geográfico, a primeira apontando para teorização matemática sobre os aspectos naturais, e a segunda 
pautada na experiência elementar extraída das relações com a natureza. Essa divisão é bem definida quando analisamos os métodos de Bernhardus Varenius e Humboldt.

No entanto, o fator determinante que faz com que vigore um método sobre o outro é a condição necessária a época, como apresentado aqui. Havia a necessidade de estabelecer um piso para a revolução newtoniana, "era preciso refletir sobre a construção de uma unidade na multiplicidade de fenômenos que aconteciam na superfície da Terra, para, a partir disso, serem elaboradas estratégias comerciais e mesmo de dominação política" (VITTE, 2013, p.201).

Embora seja antecessor de Humboldt, o método geográfico de Varenius "abriu as janelas da modernidade no mundo ocidental, apenas porque foi a primeira obra cientifica a utilizar preceitos de Galileu Galilei, Kepler, Descartes e Newton”(VITTE, 2013, p.201).

Diante do paradoxo existente entre base e topo em uma escala temporal do pensamento geográfico, nota-se o abismo vivenciado atualmente entre homem e mundo, percepções sugeridas que, no âmbito da geografia, contida nos livros didáticos, o mundo em seu contexto heliocêntrico, necessariamente é parte cabida às reflexões dos geógrafos.

\section{CONSIDERAÇÕES FINAIS}

$\mathrm{Na}$ base do pensamento geográfico ainda reside a questão. Em uma aproximação mais apurada a este, percebe-se que sua função "geográfica" de descrever o mundo é sabotada por outras ciências, fato esse que o afasta da discussão sobre a propagação da ideia de uma terra plana.

A questão é que o fenômeno de multiplicação desse discurso está posto, e corriqueiramente é trazido à tona por uma diversidade de agentes. Cabe à geografia atenção ao caso, não pelo formato do planeta em si, mas pela verificação de seu método frente a dúvida latente e a não correspondência do senso científico.

\section{REFERÊNCIAS}

BAUAB, F. A geografia geral (1650) de Bernhardus Varenius: a modernidade da obra. Revista RA`E GA 23 O Espaço Geográfico em Análise, Curitiba, v.23, p. 191 - 220, 2011

BRITO, A. de Jesus and SCHUBRING, G. Varenius e o conhecimento matemático do século XVII. Revista Ciência \& Educação, Bauru, v. 15, n. 1, p. 139-153, 2009. 
BRITO, T. Humboldt entre a filosofia da natureza e a ciência moderna. Revista Soc. \& Nat, Uberlândia, v. 27, n2, p. 195 - 207, 2015.

CHIBENI, S. S. Aspectos da Descrição Fisica da Realidade. Campinas, UNICAMP Centro de Lógica, Epistemologia e História da Ciência, 1997. 208 p.

FERNANDEZ-ARMESTO, F. Os Desbravadores, Companhia das letras. 2009. 183 p.

GALILEI, Galileu. Diálogo Sobre os Dois Máximos de Sistemas do Mundo Ptolomaico e Copernicano. São Paulo: Editora 34, 2011. 888 p.

HAWKING, E. O Universo Numa Casca de Noz. Reino Unido: Bantam Spectra. 2001. 224p

INGOLD, T. Estar Vivo Ensaios Sobre Movimento, Conhecimento e Descrição. Petrópolis: Vozes. 2015. 392 p.

KIMBLE, George H. T. A Geografia na Idade Média. São Paulo: Imprensa oficial, 2005. 345 .

KUHN, T. S. A revolução Copernicana. Rio de Janeiro: edições 70. 1975. 312 p.

LOURENÇO, Claudiney. Paisagem no Kosmos de Humboldt: um diálogo entre a abstração e sensibilidade. Tese (Doutorado em Geografia). 2003 - FFLCH/USP, São Paulo, 2003.

MORAES, A. C. R. d. A Gênese da Geografia Moderna. São Paulo: Hucitec Annablume. 2002. 202p.

MORRIS, R. Uma Breve História do Infinito. Rio de Janeiro: Jorge Zahar. 1998. 229 p. REALE, Giovanni. ANTISERI, Dario. História da filosofia: do Humanismo a Kant volume 2. São Paulo: Paulus, 2007. 950 p.

VITTE, A. A reforma Teológica, Benhart Varenious e a constituição da ciência geográfica Revista Geografares, Vitória, n.14. p.84 - 106, junho 2013. 